\title{
Drainage of Small Volume Reservoirs on the Technogenic Territories
}

\author{
Yana Davydova ${ }^{1}$, Yulia Volkova $^{1}$, Aleksandr Nikonorov $^{1 *}$ and Maksim Aleksandrovskiy ${ }^{2}$ \\ ${ }^{1}$ Peter the Great St.Petersburg Polytechnic University, Polytechnicheskaya, 29, St. Petersburg, \\ 195251, Russia \\ ${ }^{2}$ Moscow State University of Civil Engineering, Yaroslavskoe shosse, 26, Moscow, 129337, Russia
}

\begin{abstract}
The development of residential construction on alluvial territories requires high-quality engineering background in the initial stages of development. In the area with high ground moisture, the erection of buildings is difficult and drainage measures are required. The necessity to choose the method of wastewater disposal on alluvial territories has become an urgent problem, because the quality and operational characteristics of the construction depend on the correct engineering preparation of the territory, as well as the stability and capital of the buildings and structures being erected. The purpose of the work was to develop a method for the diversion of water from undesirable small reservoirs of anthropogenic origin. Approbation of method was carried out on the example of a temporary reservoir formed on the territory of a residential complex of the wash-up area of the Vasilievsky Island, St. Petersburg, where engineering training is intensively underway. The implementation of proposed method is stated.
\end{abstract}

\section{Introduction}

Currently, there is an urgent problem of temporary undesirable man-caused reservoirs of small volume [1-4]. Often and being the most "inconvenient" such water reservoirs occur in the following cases:

1) in depressions of solid waste landfills;

2) pumping water from the excavation to the relief when building facilities on the territory of construction sites.

Hundreds thousands of tons of household waste are accumulated annually in urban landfills [5]. Being decomposed, domestic waste poisons air, soil, and underground water with dangerous toxins that spread sewage and thus become a serious danger to the environment and human [1]. The need for disposal of storm water overflow from landfill sites is relevant from the time of their formation and to the present, because the formation of garbage dumps from various wastes is a global environmental problem throughout the world $[6,7]$.

\footnotetext{
* Corresponding author: coolhabit@yandex.ru
} 
Sewage storm water at the landfills is contaminated not only mechanically, but chemically hazardous substances, therefore, such water should be diverted to special waterloss accumulators, after which water purification takes place [8]. The water from the pits is often pumped out not to water receivers, but directly on the relief, due to the growth of residential construction and the desire to reduce costs. The consequences of a free outflow on the terrain are a decrease in the bearing capacity of the basement and the suffusion of the soil [9-11]. Temporary anthropogenic water reservoirs occupy the useful area of the territory for building, the possibility of free movement of pedestrians and transport, negatively affect the sanitary norms and aesthetic appearance in general [7].

The alluvial territories on Vasilievsky Island today already represent a completely autonomous microdistrict, where a number of residential complexes are being actively built,so as the large public and business center, and a seaport. However, the problem of wastewater disposal at construction sites in the construction of residential complexes is not solved. On the alluvial territories of Vasilievsky Island allocated for the development of the residential complex «Ya - Romantic. Svetliy Put» (Fig. 1) the volume of groundwater during the development of the pit was directed to a relief that was not designed for open water drainage, which led to the formation of a temporary reservoir, which requires the fastest possible utilization. The considered site with an anthropogenic undesirable reservoir is in the immediate vicinity of the Gulf of Finland (Fig. 2).

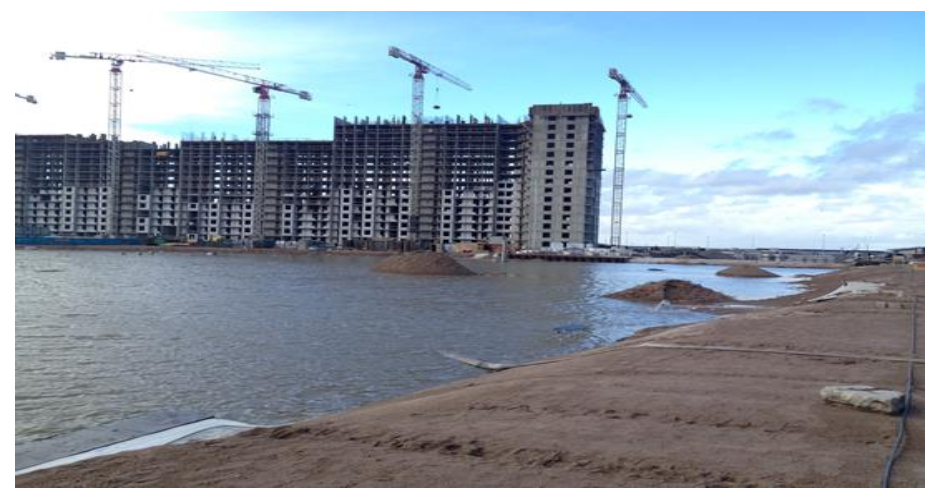

Fig.1. The layout of the residential complex on Vasilievsky Island.

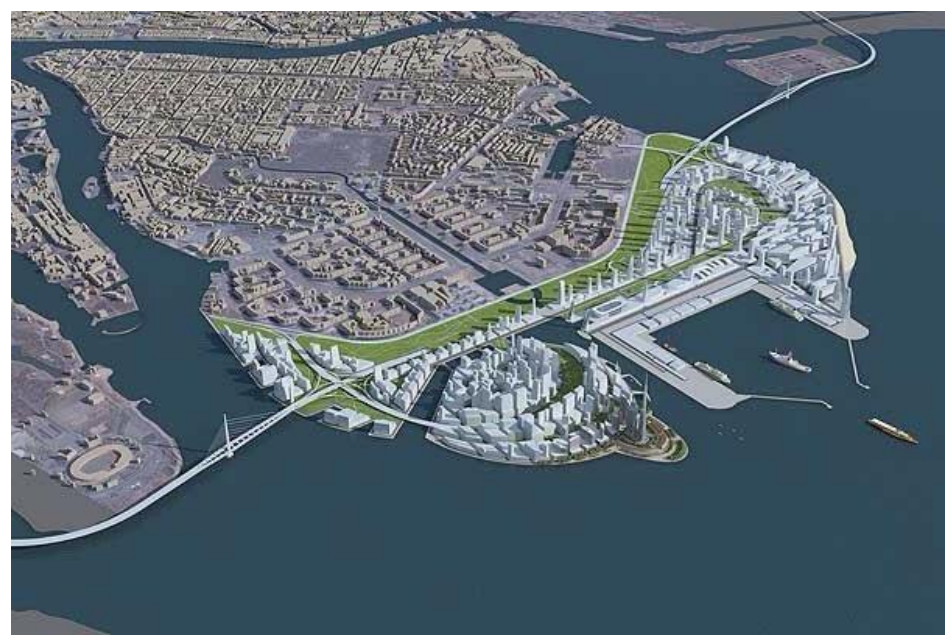

Fig.2. Scheme of location of the alluvial territories relative to the Gulf of Finland. 


\section{Materials and methods}

There are two possible options for draining this and similar temporary reservoirs in the following ways:

1) by gravity discharge through the channel connecting the temporary pond with the Gulf of Finland (or another natural or artificial water intake);

2) pumping out the volume of water by means of a submersible pump taking water from a temporary reservoir and dropping it into the Gulf of Finland (or other natural or artificial water intake).

Engineering preparation and protection of the building site should be carried out at the initial stages of construction in order to ensure the continuity and quality of work on which the safety and comfort of the population depends [11-13].

Let's consider both the proposed methods. As the proposed for implementation, we take the cheapest.

\subsection{Water discharge through the channel}

A - volume of temporary reservoir $-2000 \mathrm{M}^{3}$. Take the channel width along the bottom - $\mathrm{b}$ - on the terms of production equal to $0.5 \mathrm{~m}$ (excavator bucket width). Flow rate $\mathrm{V}$ is equal to the non-washable for sand $(\mathrm{V}=0.3 \mathrm{~m} / \mathrm{s})$. The Chezy formula was applied:

$$
Q=\omega * \mathrm{X} * \sqrt{R * I}
$$

where $\omega$ - area of the flow cross-section, $\mathrm{m}^{2}$; C - coefficient of Chezy; R - hydraulic radius, $\mathrm{m}$; I - longitudinal slope of the channel angle (in the considered case is taken as the ratio of the difference in the minimum mark of the water surface in the pumped out basin and the water mark in the Gulf of Finland to the length of the ditch); $I=(1,00 \mathrm{~m}-0,00 \mathrm{~m})$ / $500 \mathrm{~m}=0,002)$. The coefficient of Chezy is determined by the formula:

$$
C=\frac{1}{n} * R^{\frac{1}{6}}
$$

where $\mathrm{n}-$ The roughness factor of the channel channel, which is determined the normatives. Consider $\mathrm{n}=0.0275$.

At a given flow rate $\mathrm{V}=0.3 \mathrm{~m} / \mathrm{s}$ reversely identify the value of the hydraulic flow radius $\mathrm{R}$. With a known slope $\mathrm{I}=0.002 \mathrm{R}=0.1 \mathrm{~m}$.

Assuming in the first approximation that in the spaced beds the hydraulic radius is approximately equal to the average depth, we obtain an approximate value of the crosssectional area $\omega=\mathrm{b} * \mathrm{R}=0.5 * 0.1=0.05 \mathrm{~m}^{2}$.

With this area and the accepted flow rate $\mathrm{V}=0.3 \mathrm{~m} / \mathrm{s}$, the flow rate of the channel will be $\mathrm{Q}=0.3 * 0.05=0.015 \mathrm{~m}^{3} / \mathrm{s}$. Thus, the specified volume of the temporary watercourse will be pumped out over time $\mathrm{t}=\mathrm{A} / \mathrm{Q}=133333 \mathrm{~s}=37 \mathrm{~h}$.

The price of excavation under the channel by a mechanized method of $1 \mathrm{~m}^{3}$ averages from 150 rubles. The cost of development of the calculated channel will be 83025 rubles.

\subsection{Pumping through a pipeline}

Assumed that the water is pumped out by a standard submersible sewage pump, which delivers the flow into the pipeline with a diameter $\mathrm{d}=0,05 \mathrm{~m}$. We also assume that the maximum geometric pressure, overcome by the pump $\mathrm{Hg}$ equal to $0,5 \mathrm{~m}$ (the difference between the highest point in the terrain along which the pipeline passes and the minimum mark of the surface of the pumped out basin). In order to select the pump it is necessary to know: 
1. Design pressure and pump supply;

2. Pipeline characteristics $(\mathrm{Q} \div \mathrm{H})_{\mathrm{p}}$ B in the form of the table.

For an approximate calculation, the working pressure in the pipeline can be adopted by formula:

$$
H_{w}=H_{g}+V h_{p p}
$$

where $\Delta \mathrm{h}_{\mathrm{pp}}$. - pressure loss in the pipeline, $\mathrm{m}$. The loss of pressure in the pipeline is composed of losses along the length and local pressure losses:

$$
\mathrm{V} h_{p p}=\lambda \frac{L}{d} * \frac{V^{2}}{2 g}
$$

where $\lambda$ - coefficient of hydraulic resistance; 1- length of pipeline, $\mathrm{m}$; d- diameter of suction pipe, $\mathrm{m} ; \mathrm{g}$ - acceleration of gravity, $10 \mathrm{~m} / \mathrm{s}^{2}$.

Reynolds number:

$$
R_{e}=\frac{V * d}{v}
$$

where $v=1.307 \mathrm{~m}^{2} / \mathrm{s}^{*} 10^{-6}-$ coefficient of kinematic viscosity. Coefficient of hydraulic resistance $\lambda$ :

$$
\lambda=\frac{0.3164}{R_{e}^{0.25}}
$$

Local hydraulic pressure losses are calculated using the Darcy formula:

$$
h_{l}=\xi * \frac{V^{2}}{2 g}
$$

where $\zeta=1$, local loss ratio. Calculation is made for several feed rates to build the pressure characteristic of the pipeline.

\section{Results and discussions}

The results of the calculations are recorded in Table 1.

Table 1. Pressure characteristic of the pipeline.

\begin{tabular}{|l|l|l|l|l|l|}
\hline $\mathbf{Q}, \mathbf{l} / \mathbf{s}$ & $\mathbf{V}, \mathbf{m} / \mathbf{s}$ & $\mathbf{R e}$ & $\boldsymbol{\lambda}$ & $\mathbf{h}, \mathbf{m}$ & $\mathbf{H}, \mathbf{m}$ \\
\hline 0,56 & 0,30 & 11094 & 0,030 & 1,294 & 1,794 \\
\hline 1,11 & 0,60 & 21423 & 0,026 & 4,176 & 4,676 \\
\hline 1,67 & 0,80 & 33282 & 0,023 & 8,921 & 9,421 \\
\hline 2,22 & 1,40 & 428462 & 0,022 & 14,144 & 14,644 \\
\hline 2,78 & 1,40 & 54705 & 0,021 & $22,0,14$ & 22,514 \\
\hline 3,33 & 2,00 & 76511 & 0,022 & 45,10 & 45,6 \\
\hline 3,89 & 2,1 & 84162 & 0,019 & 47,147 & 47,647 \\
\hline
\end{tabular}


Analyzing modern pumps that offer domestic and foreign markets, it can be concluded that the working pressure of a submersible pump, designed for a relatively small flow of water, ranges from 5 to $14 \mathrm{~m}$. Pumps with a large head are designed for a large feed, which does not satisfy specific conditions (Fig. 3).

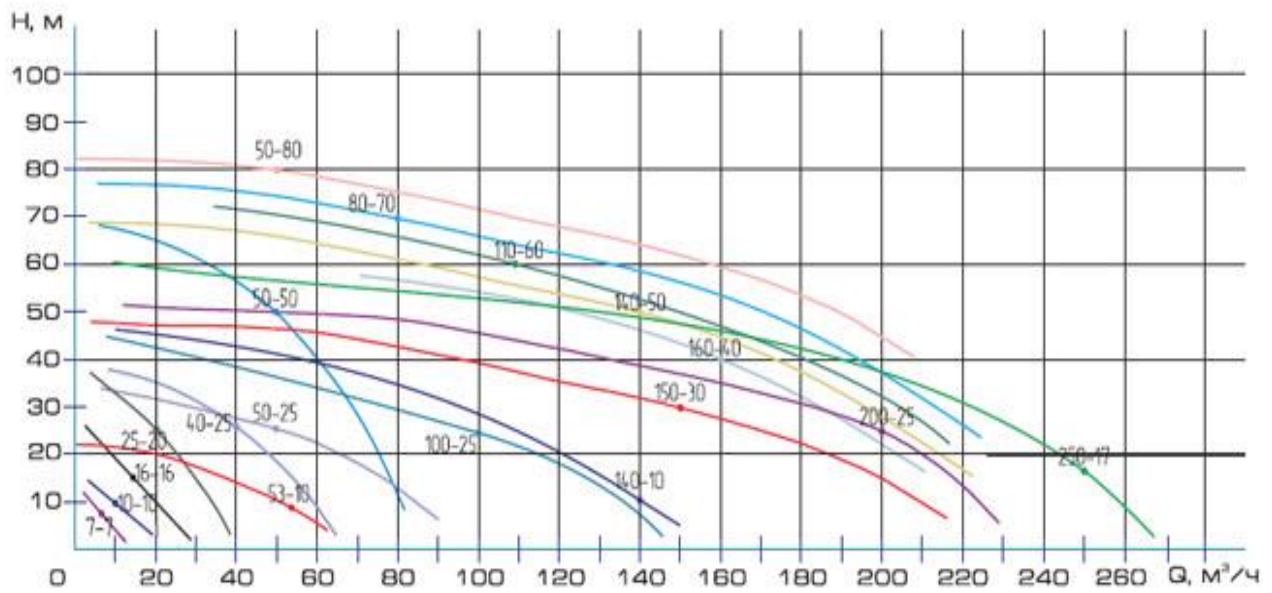

Fig.3. Characteristics of submersible electric pumps.

According to the table, this pressure corresponds to the supply $Q=2,11 / \mathrm{s}$. These parameters are met by the pump «Drainage» 220/14 of Russian production. The cost of this pump is 4.200 rubles, and the price per meter of rubber pressure hose is 330 rubles. The total cost of this drainage plant is 169.200 rubles.

The decision to use one of the proposed methods is made on the basis of economic comparison of options or based on a specific situation. Based on the results of calculations, it is advisable to use the open drainage method for draining small volumes of soils on which work is done, which benefits in many respects:

-ease in technology of erection;

-speed of erection;

-ease and speed of elimination;

-environmentally friendly;

- low labor costs and cost indicators.

When the water is pumped, the characteristic of the pipeline could be built, along which the pump is selected and the pumping time is determined. The costs of pumping out add up to the cost of the pump and the pipeline (or their lease) and the cost of electricity expended. In order to receive the full picture of soil properties in the considered area, during the engineering preparations [14-17], it is necessary to investigate the hydrophysical properties of the soil [17-20], moreover in case of hydraulic engineering [21-26] .

\section{Summary}

In this paper, authors considered two of the simplest existing methods of wastewater disposal. For a given volume of pumped water, slope and width of the discharge channel, a hydraulic calculation is made, from which the flow and time of the liquidation was determined, the time of water evacuation from the channel was determined, and the expenses for excavation were calculated in the development of the canal for drainage of the temporary reservoir. The choice of the drainage method of temporary anthropogenic water reservoirs was justified by a technical and economic comparison. Comparing the costs of 
draining a temporary reservoir, it can be concluded that for specific conditions it is economically profitable to produce it by developing a trench in a mechanized way, which costs almost 3 times less than using a submersible pump with a pipeline. The proposed method should be used comparatively with the complex research of construction site soil properties.

\section{Acknowledgments}

The work is supported by RFBR (No. 16-04-01473-a).

\section{References}

1. M.V. Romanov, A. Tarakanov, ECOBALTICA 2000 Proceedings Book, 2000, 225230 (2001).

2. O.D. Lukashevich, Journal of Water Chemistry and Technology, 28(2), 58-65 (2006).

3. M.J. Deitch, A.M. Merenlender, S. Feirer, Water Resources Management, 27, 51015118 (2013).

4. Q. Tang, H. Gao, F. Su, D.P. Lettenmaier, P. Yeh, T. Oki, Journal of Hydrometeorology, 11, 156-170 (2010).

5. C.J. Vörösmarty, B. Fekete, P. Green, M. Meybeck, K. Sharma, J.P.M. Syvitski, Global and Planetary Change, 39, 169-190 (2003).

6. M. Yakovleva, E. Frolov, V. Isayev, S. Zubanov, MATEC Web of Conferences, 2017, Article number 00180 (2017).

7. S.L. Houston, C.E. Zapata, W.N. Houston, H.B. Dye, K.D. Walsh, Journal of Performance of Constructed Facilities, 25, 31-44 (2011).

8. T. Orlova, A. Melnichuk, K. Klimenko, V. Vitvitskaya, V. Popovych, I. Dunaieva, V. Terleev, A. Nikonorov, I. Togo, Yu. Volkova, W. Mirschel, V. Garmanov, IOP Conference Series: Earth and Environmental Science, 90, article number 012110 (2017).

9. J.L. van Rooy, J.S. Stiff, Bulletin of Engineering Geology and the Environment, 59, 0285-0295 (2001).

10. H. Nouri, S. Beecham, F. Kazemi, A.M. Hassanli, Urban Water Journal, 10, 247-259 (2013).

11. R.A. Poluektov, V.V. Terleev, Russian Meteorology and Hydrology, 12, $73-77$ (2005).

12. V.V. Terleev, A.G. Topazh, W. Mirschel, Russian Meteorology and Hydrology, 40(4), 278-285 (2015).

13. V.V. Terleev, A.O. Nikonorov, I. Togo, Yu.V. Volkova, R.S. Ginevsky, V.A. Lazarev, E.R. Khamzin, V.V. Garmanov, W. Mirschel, L.I. Akimov, Magazine of Civil Engineering, 2, 84-92 (2017).

14. V.N. Zhilenkov, Z.G. Vasil'eva, Power Technology and Engineering, 37, 19-23 (2003).

15. M.S.O. Ilha, L.H. Oliveira, O.M. Gonsalves, Building Services Engineering Research and Technology, 30, 15-26 (2009). 
16. V.V. Terleev, W. Mirschel, V.L. Badenko, I.Yu. Guseva, Eurasian Soil Science, 50(4), 445-455 (2017).

17. H. Nouri, S. Beecham, S. Anderson, A.M. Hassanli, F. Kazemi, Urban Water Journal, 12, 380-393 (2015).

18. N. Ursino, Urban Water Journal, 14, 509-514 (2017).

19. N. Arefiev, V. Garmanov, V. Bogdanov, Yu. Ryabov, V. Terleev, V. Badenko, Procedia Engineering, 117, 26-31 (2015).

20. A. Nikonorov, S. Pavlov, V. Terleev, N. Arefiev, V. Badenko, Yu. Volkova, Procedia Engineering, 117, 258-263 (2015).

21. N. Arefiev, V. Terleev, V. Badenko, Procedia Engineering, 117, 39-44 (2015).

22. V. Badenko, V. Terleev, A. Topaj, Applied Mechanics and Materials, 635-637, 16881691 (2014).

23. A. Makarov, A. Mihailova, N. Arefiev, S. Pavlov, T. Chashchina, V. Terleev, V. Badenko, Procedia Engineering, 117, 225-231 (2015).

24. S. Medvedev, A. Topaj, V. Badenko, V. Terleev, IFIP Advances in Information and Communication Technology, 448, 252-261 (2015).

25. V.V. Terleev, W. Mirschel, U. Schindler, K.-O. Wenkel, Journal International Agrophysics, 24(4), 381-387 (2010).

26. N. Arefiev, V. Badenko, A. Nikonorov, V. Terleev, Yu. Volkova, Procedia Engineering, 117, 20-25 (2015). 